\title{
Velloziaceae endémicas del Perú
}

Blanca León ${ }^{1,2}$

${ }^{1}$ Museo de Historia Natural, Av. Arenales 1256, Aptdo. 14-0434, Lima 14, Perú

2 Plant Resources Center, University of Texas at Austin, Austin TX 78712 EE.UU.

blanca.leon@mail.utexas.edu

\section{Resumen}

La familia Velloziaceae está representada en el Perú solamente por un género, Barbaceniopsis, y una especie arbustiva (Brako \& Zarucchi, 1993). En este trabajo reconocemos el endemismo de esta especie, la cual se distribuye en matorrales de valles interandinos de la región Mesoandina, entre los 2100 y 2900 m de altitud. No está representada dentro de áreas naturales protegidas.

Palabras claves: Velloziaceae, Perú, endemismo, plantas endémicas.

\section{Abstract}

The Velloziaceae are represented in Peru by one genus, Barbaceniopsis, and one shrubby species (Brako \& Zarucchi, 1993). Here we recognize this species as endemic; it grows in shrublands of interandean valleys of the Mesoandean region, between 2100 and 2900 $\mathrm{m}$ elevation. It has not been reported to date from a Peruvian protected area.

Keywords: Velloziaceae, Peru, endemism, endemic plants.

1. Barbaceniopsis vargasiana (L.B. Sm.) L.B. Sm.

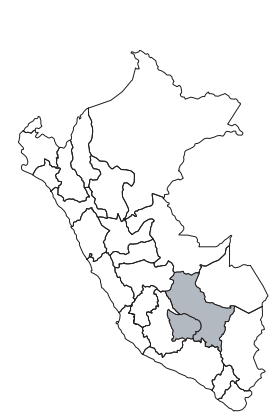

$$
\text { VU, B1a }
$$

Publicación: Contr. U.S. Natl. Herb. 35(4): 271. 1962.

Colección tipo: C. Vargas C. 4883

Herbarios: GH, US.

Nombre común: Desconocido.

Registro departamental: AP, CU.

Regiones Ecológicas: MA; 2100—2900

$\mathrm{m}$.

SINANPE: Sin registro.

Herbarios peruanos: CUZ (5).

Observaciones: Hierba conocida de laderas con matorrales semixéricos de la cuenca del Apurímac. Aparentemente, su distribución se extienda a la Amazonía, pero el ejemplar no pudo verificarse. Aquí se considera esta especie restringida a las partes montanas del sur del país. 